\title{
Modern Microscopy to Address the Grand Challenges of Corrosion
}

\author{
William M. Kane
}

Exponent Failure Analysis Associates, Philadelphia, PA, USA

In 2011, the National Academy of Sciences issued a report entitled, Research Opportunities in Corrosion Science and Engineering [1]. Recognizing the difficulty for advancement in a critical field that unfortunately suffers from a moribund perception, the Academy set out to establish a set of grand challenges for corrosion science and engineering. The authoring committee, composed of both corrosion experts and experts from complementary fields, identified four principal grand challenges: (1) Development of cost-effective, environment-friendly corrosion-resistant materials and coatings; (2) High-fidelity modeling for the prediction of corrosion degradation in actual service environments; (3) Accelerated corrosion testing under controlled laboratory conditions that quantitatively correlates to observed long-term behavior in service environments; and (4) Accurate forecasting of remaining service time until major repair, replacement, or overhaul becomes necessary.

In support of these challenges, the Academy also identified corrosion research opportunities from the perspective of both the top-down technological needs of society and bottom-up advancements in fundamental science. The research areas they identified were replete with opportunities brought about by advancements in microscopy and microanalysis tools and techniques, and will undoubtedly lead to a more thorough understanding of material failures due to corrosion. A review of several the techniques identified by the committee, and the advancement of microscopy in the analysis of environmental degradation is the subject of this presentation.

The utility of microscopy is well recognized in corrosion research in the sense that electrochemical mechanisms typically function at length scales commensurate with one or more of several microscopy techniques. Optical and scanning electron microscopy is a fundamental tool for the diagnosis of environmental degradation and any complete failure analysis of a corroded component with likely include an evaluation of the morphologies and microstructures accessible by these techniques. It has remained difficult however to perform quantitative or in-situ analyses, where modern means pose the greatest opportunity for advancement.

We will explore techniques such as microtomography (Figure 1), scanning transmission and low-voltage electron microscopy, scanning electrochemical microscopy and mapping, and scanning probe techniques, which promise far greater understanding over the time and length scales currently studied experimentally. From these techniques for example, analytical electron microscopy offers highresolution chemical analysis, machining precision thinned sections of oxidized material from a corroded specimen is possible using focus ion beam techniques, and wet in-situ observations are now possible on metallic and polymeric materials [2-3]. These tools will advance our understanding of the heterogeneous aspects of corrosion, and lead to a better understanding of the nanolength scale phenomena such as absorption, passivity and dissolution that may either prevent or lead to material failures so that we can meet the Academy's grand challenges in the future. 


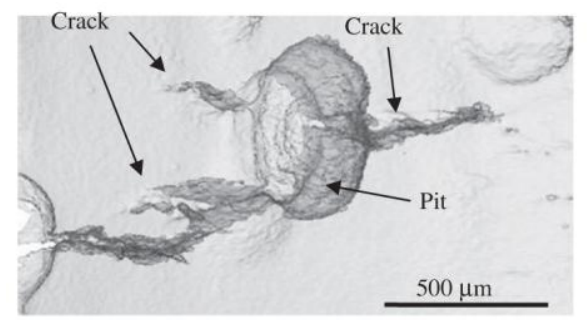

(a)

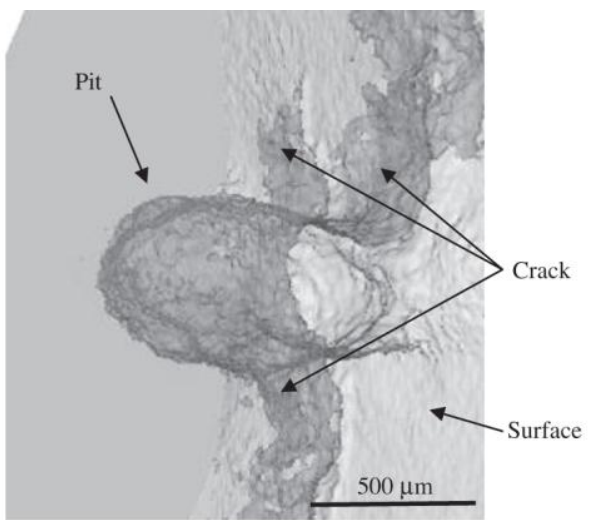

(b)

Figure 1. 3D tomographic reconstruction of pit-to-crack specimen. (a) surface view, (b) internal reconstruction. From Horner, D.A., et al., Corrosion Science, 53 (2011), p. 3466.

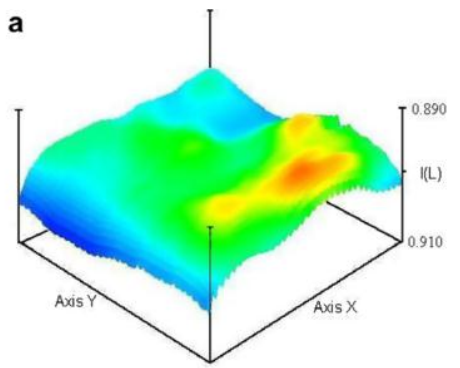

\section{b}

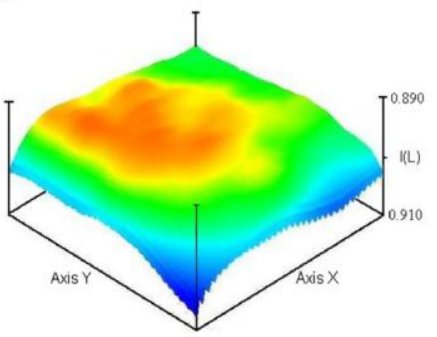

c

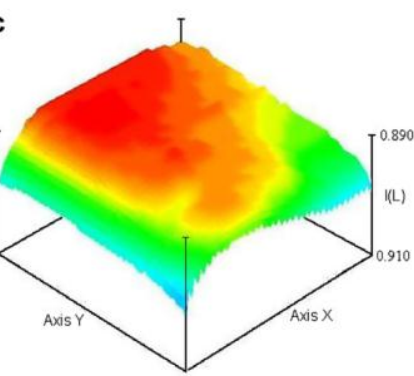

d

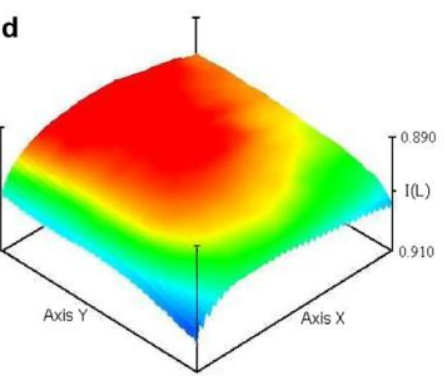

$\begin{array}{llllllll}0.891 & 0.893 & 0.895 & 0.897 & 0.899 & 0.901 & 0.903 & 0.905\end{array}$

I(L)

Figure 2. Scanning electrochemical microscopy images of polyester-coated steel containing a galvanized layer during its immersion in $0.1 \mathrm{M} \mathrm{KCl}$ solution after (a) $16 \mathrm{~min}$, (b) $75 \mathrm{~min}$, (c) $9 \mathrm{~h}$ and (d) 24 h. Current I(L) is in nA. From Souto, R.M., et al., Corrosion Science, 50 (2008), p. 1637.

[1] National Research Council (U.S.). Committee on Research Opportunities in Corrosion Science and Engineering., National Research Council (U.S.). National Materials Advisory Board., and National Academies Press (U.S.), Research opportunities in corrosion science and engineering / Committee on Research Opportunities in Corrosion Science and Engineering, National Materials Advisory Board, Division on Engineering and Physical Sciences, National Research Council of the National Academies2011, Washington, D.C.: National Academies Press. xv, 176 p.

[2] Haynes, J.A., Pint, B.A., More, K.L., et al., Oxidation of Metals, 58 (2002), p. 513.

[3] Gonzalez, S., Santana, J.J., Garcia, Y., et al., Corrosion Science, 53 (2011), p. 1910. 